\title{
Cells in Auditory Cortex that Project to the Cochlear Nucleus in Guinea Pigs
}

\author{
Brett R. Schofield, Diana L. Coomes, and Ryan M. Schofield \\ Department of Neurobiology, Northeastern Ohio Universities College of Medicine, 4209 St. Rt. 44 P.O. Box 95, Rootstown, \\ $\mathrm{OH}$ 44272, USA
}

Received: 22 March 2004; Accepted: 7 December 2005; Online publication: 24 March 2006

\begin{abstract}
Fluorescent retrograde tracers were used to identify the cells in auditory cortex that project directly to the cochlear nucleus $(\mathrm{CN})$. Following injection of a tracer into the $\mathrm{CN}$, cells were labeled bilaterally in primary auditory cortex and the dorsocaudal auditory field as well as several surrounding fields. On both sides, the cells were limited to layer $\mathrm{V}$. The size of labeled cell bodies varied considerably, suggesting that different cell types may project to the CN. Cells ranging from small to medium in size were present bilaterally, whereas the largest cells were labeled only ipsilaterally. In optimal cases, the extent of dendritic labeling was sufficient to identify the morphologic class. Many cells had an apical dendrite that could be traced to a terminal tuft in layer I. Such "tufted" pyramidal cells were identified both ipsilateral and contralateral to the injected $\mathrm{CN}$. The results suggest that the direct pathway from auditory cortex to the cochlear nucleus is substantial and is likely to play a role in modulating the way the cochlear nucleus processes acoustic stimuli.
\end{abstract}

Keywords: auditory system, pyramidal cells, layer $\mathrm{V}$, neuroanatomy, descending system, efferent system

Correspondence to: Brett R. Schofield • Department of Neurobiology • Northeastern Ohio Universities College of Medicine • 4209 St. Rt. 44 P.O. Box 95, Rootstown, OH 44272, USA. Telephone: 330-3256655; fax: 330-325-5916; email: bschofie@neoucom.edu

\section{INTRODUCTION}

The auditory cortex (AC) is the origin of a large set of descending pathways that can affect neural processing at every level of the auditory system (reviewed by Harrison and Howe 1974; Faye-Lund 1985, 1986; Huffman and Henson 1990; Spangler and Warr 1991; Saldaña 1993; Rouiller 1997; Zhang et al. 1997; Suga et al. 2000). For example, performance of an auditory reaction time task, which requires increased attentiveness, alters the responses of single units in the cochlear nucleus, superior olivary complex, inferior colliculus, and thalamus to acoustic stimuli (Ryan et al. 1984). Proposed functions of the descending pathways include selective attention, frequency selectivity, differential gating of afferent information, differential conditioning (presumably reflecting cellular aspects of learning), intensity coding, sound localization, adjustment of dynamic range, modulation of temporal processing, discrimination of speech sounds, and long-term plasticity in functional organization of subcortical structures (e.g., Desmedt 1960, 1962; Dewson et al. 1966; Ryan and Miller 1977; Ryugo and Weinberger 1976, 1978; Ryan et al. 1984; Scharf et al. 1987; Puel et al. 1988; Rajan 1990; Yan and Suga 1996; Giraud et al. 1997; Zhang and Suga 1997; Jen et al. 1998; reviewed by Huffman and Henson 1990; Spangler and Warr 1991; Rouiller 1997; Suga et al. 2000). This wide array of functions has led to increasing interest in the underlying circuitry, particularly with the discovery that newly developed anatomical tracers can reveal previously unknown pathways (e.g., Feliciano et al. 1995).

In 1964, Zimmerman et al. provided evidence of direct cortical projections to the cochlear nucleus 
(CN) in rats (Zimmerman et al., 1964). This pathway received little further attention until 1995, when Feliciano et al. used newly developed tracers to describe the subcollicular projections of auditory cortex in detail (Feliciano et al. 1995). The results confirmed the previously described projection and suggested that there are multiple pathways by which the AC can affect brainstem auditory circuits. Weedman and Ryugo (1996b) identified pyramidal cells in layer V of primary auditory cortex as the origins of these projections. The same authors identified granule cells in the $\mathrm{CN}$ as a direct target of the cortical projections (Weedman and Ryugo 1996a), suggesting that $\mathrm{CN}$ interneurons could be the primary target of cortical projections.

Subsequent studies demonstrated a cortical projection to the $\mathrm{CN}$ in guinea pigs (Jacomme et al. 2003; Schofield and Coomes, 2005a). The results were similar to those described in rats, with a notable exception that the cortical axons appeared to terminate not only in the granule cell area (like in rats) but also in the magnocellular parts of both the dorsal and ventral CN (Jacomme et al. 2003; Schofield and Coomes, 2005a). The latter result raised the possibility that cortical axons make direct contact with $\mathrm{CN}$ principal cells. A recent multi-labeling study has provided support for this idea, showing that cortical axons are likely to make direct contact with $\mathrm{CN}$ cells that project to the inferior colliculus (Schofield and Coomes, 2005b).

Another apparent difference between rats and guinea pigs is in the distribution of cortical cells that project to the CN. In rats, all such cells are located in primary auditory cortex (Weedman and Ryugo 1996a). However, anterograde tracing studies in guinea pigs suggest that both of the large "core" auditory areas, the primary auditory cortex and the dorsocaudal field, project directly to the CN (Jacomme et al. 2003; Schofield and Coomes, 2005a). Finally, the laterality of the projections may also differ between rats and guinea pigs. In rats, both anterograde and retrograde tracing studies indicate a predominantly ipsilateral projection. In contrast, the anterograde studies in guinea pigs showed an ipsilateral predominance in some animals and a contralateral predominance in others.

The present study employs retrograde tracers in guinea pigs to try to clarify several issues. First we wished to assess the distribution of cortical cells that project to the $\mathrm{CN}$, both with respect to cortical areas and to ipsilateral versus contralateral predominance. Second, we hoped to identify the type(s) of pyramidal cells that project to the CN. Layer V contains two main types of pyramidal cells that differ in morphology and physiology (e.g., Mitani et al. 1985; Ojima et al. 1992; Winer 1992; Hefti and Smith 2000, 2003;
Winer and Prieto 2001). It is not clear which of the types project to the $\mathrm{CN}$.

\section{MATERIALS AND METHODS}

\section{Surgery}

Twenty-four Hartley guinea pigs (Charles River Laboratories, Wilmington, MA) received injections of retrograde tracers into one or both cochlear nuclei. One additional control animal received injections into the left and right cerebellum (including the middle and inferior cerebellar peduncles) dorsal to the CN. All procedures followed NIH guidelines for animal care and were approved by the Institutional Animal Care and Use Committee. All surgical procedures were carried out with aseptic technique. Each animal was anesthetized with halothane (3.5-4.0\% for induction; $2.25-3.0 \%$ for maintenance) in a mixture of nitrous oxide and oxygen. Atropine sulfate $(0.08 \mathrm{mg} / \mathrm{kg}$ i.m.) was given to minimize bronchial secretions. Each cornea was protected by a coating of Neosporin ophthalmic solution. The animal's scalp was disinfected with polyhydroxydine solution (Solvay Veterinary, Inc., Princeton, NJ) and shaved. The animal was then placed on a feedback-controlled heating pad and mounted in a stereotaxic frame modified for gas anesthesia. An incision was made in the scalp and the wound margins were injected with $0.25 \%$ bupivacaine, a long-lasting local anesthetic (Sensorcaine, Astra Pharmaceutical Products, Westborough, MA). A craniotomy was made on one or both sides to allow insertion of a 10- $\mu$ l Hamilton syringe guided by stereotaxic coordinates. Injections of $0.15-0.25$ $\mu \mathrm{l}$ were made at each of one to four sites within the CN. In some animals, a second tracer was injected into the $\mathrm{CN}$ on the opposite side. Six fluorescent tracers were used in this study: Fast Blue (5\% aqueous solution, Sigma, Inc., St. Louis, MO), FluoroGold (4\% aqueous solution; FluoroChrome Inc., Engelwood, CO), FluoroRuby (tetramethyl rhodamine-conjugated dextran, MW $=10,000 ; 10 \%$ in saline; Molecular Probes, Inc., Eugene, OR), fluorescein dextran (MW $=10,000 ; 10 \%$ in saline; Molecular Probes, Inc., Eugene, OR), and red or green latex microspheres ("beads," undiluted, Luma-Fluor, Inc., Naples, FL). In animals that received bilateral injections, the two tracers were always of different colors. Following injections, the syringe was removed and Gelfoam (Harvard, Inc., Holliston, MA) was placed over each craniotomy. The scalp was sutured and the animal was returned to its cage, where it was monitored until it regained the ability to walk and eat normally. It was then returned to the animal facility. 
Fixation and tissue processing

After 5-19 days to allow for axonal transport, the animal was killed by overdose of sodium pentobarbital $(440 \mathrm{mg} / \mathrm{kg}$ i.p.) or by inhalation of carbon dioxide. Once breathing had stopped and corneal and withdrawal reflexes had disappeared, the animal was perfused through the aorta with Tyrode's solution followed by $300 \mathrm{ml}$ of $4 \%$ paraformaldehyde in $0.1 \mathrm{M}$ phosphate buffer ( $\mathrm{pH} 7.4)$ and then by $300 \mathrm{ml}$ of the same fixative with $10 \%$ sucrose added. The brain was removed and stored at $4^{\circ} \mathrm{C}$ in the same fixative with $30 \%$ sucrose.

The brain was frozen and cut at a thickness of 40 or $50 \mu \mathrm{m}$. In most cases, the cortex was separated from the brainstem to be cut separately. The cortical sections were cut in the transverse plane; brainstem sections were cut in the sagittal or transverse plane. In a small number of cases, all the cortical sections were mounted in serial order to facilitate reconstruction of labeled dendritic trees. In the majority of cases, the sections were collected in six series. At least three series of sections were mounted on slides, airdried overnight, and coverslipped with DPX (Aldrich Chemical Co., St. Louis, MO) for viewing of fluorescence. An additional series of sections was mounted on slides and stained with thionin for identification of brainstem nuclei and cortical layers.

\section{Data analysis}

The slides were viewed with a Zeiss Axioskop equipped with a camera lucida and digital camera (described below). Injection sites were drawn with the camera lucida or with a Neurolucida reconstruction system (MicroBrightField, Colchester, VT) attached to a Zeiss Axioplan II microscope. Cytoarchitectonic borders were added by comparison with adjacent, thioninstained sections. Borders within the cochlear nuclei were determined according to Hackney et al. (1990). Labeled cortical cells were observed with a $40 \times$ objective $(\mathrm{NA}=0.85)$.

In six cases, labeled cells in every 12th section (GP398) or every 24th section (remaining cases) through the temporal cortex were counted with the Neurolucida system. One of the cases had an injection into one $\mathrm{CN}$ and the other five cases had injections of different tracers in the left and right $\mathrm{CN}$. In cases with bilateral injections, a small number of double-labeled cells were observed, indicating that some cortical cells send axon branches to both CNs; these data will be analyzed and described in a future report. For the present study, the different tracers were analyzed separately, yielding 11 experiments for analysis of the number of labeled cells. Cells were counted only if the top surface of the cell was clearly contained within the section. This approach reduces the overcount associated with profile counting (cf. Guillery 2002). Additional corrections were not applied because the purpose was not to obtain a precise number of cells in the pathway but to compare the number of labeled cells on the two sides.

The locations of labeled cells were determined by plotting the labeled cells in transverse sections with the Neurolucida reconstruction system. Every 12th or 24th section through temporal cortex was plotted. Sections were aligned with multiple fiducial points, including the pseudosylvian and rhinal sulci. The sections were then rotated $90^{\circ}$ and overlaid on a photograph of the guinea pig brain. Cortical areas were identified by reference to a standardized map (Wallace et al. 2000, 2002b), which relates the auditory areas to cortical surface features (e.g., the pseudosylvian and rhinal sulci). The standardized map is limited in that the precise locations of borders of the smaller areas (the "belt" areas that surround the two large tonotopically-organized "core" areas) vary considerably from one animal to another. However, the core areas-primary auditory cortex (A1) and the dorsocaudal field-are sufficiently large that one can be confident that cells distributed across an expanse of the temporal lobe must include these fields. With these limitations in mind, the standardized map was digitized and added to the surface reconstruction, using surface landmarks to determine scale and position (see Coomes and Schofield 2004a for details of surface reconstruction and overlay of Wallace map). Given the limitations of the standardized map (see further discussion in Wallace et al. 2000), we can be most confident about the primary auditory cortex and the dorsocaudal field; conclusions regarding the surrounding belt areas will need to be confirmed with studies that include physiological identification of those fields.

Cortical layers were distinguished with a thionin stain. Figure 1 shows a section through the primary auditory cortex. The layers are similar to those described in rats (e.g., Games and Winer 1988; Roger and Arnault 1989) and are readily distinguished by similar criteria. Briefly, layer I has very few cell bodies. Layers II and III contain densely packed cells, many of which are pyramidal. A prominent layer IV is dominated by granule cells, which are smaller and rounder and packed more closely than the cells in adjacent layers. Layer $\mathrm{V}$ is characterized by a low density of cells, most of which are pyramidal in shape. Layer VI has a higher density of cells than layer $\mathrm{V}$, and the cells are generally smaller and somewhat flattened compared to those in layer V.

Photographs were taken with a cooled digital camera (Optronics Magnafire) mounted on the Axioskop microscope. The digital files were pro- 


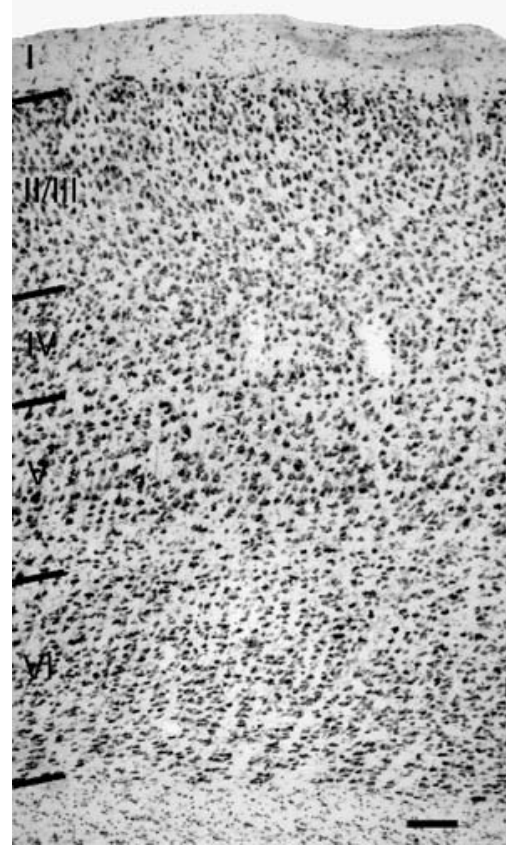

FIG. 1. Digital photomicrograph of a thionin-stained section through primary auditory cortex showing laminar borders. Scale bar $=100 \mu \mathrm{m}$.

cessed with Adobe Photoshop (Adobe, Inc., San Jose, CA). Photoshop was used to adjust brightness, contrast and gamma, to add labels, to assemble photomontages, and to place multiple images in a single plate. The images were usually converted to gray scale and, in some cases, the contrast was inverted to make the label more visible.

The cross-sectional area of labeled somata was measured in two cases. In the first case, all labeled somata in every third section through the temporal cortex were photographed as described above. The second case had fewer labeled cells, so cells from all sections through the temporal cortex were measured. The images were printed and the soma areas were measured with SigmaScan (Jandel Scientific, San Rafael, CA). Cells located ipsilateral to the injection site were compared to those contralateral to the injection. A two-sample $t$ test assuming unequal variances was used to compare the means (Microsoft Excel; $p=0.05)$.

Two methods were used for serial reconstruction of the dendritic arbors of labeled cells. In the first method, well-labeled cells were reconstructed with the camera lucida following standard procedures. In the second method, labeled structures were photographed in serial sections. The images were converted to gray scale with Photoshop as described above and stacked in layers in the order of the serial sections. Layer masks were used as necessary to hide artifactual labeling. The layers were then blended so that labeled structures were visible. Images from individual layers were aligned visually, using multiple fiducial points (e.g., blood vessels, labeled dendrites, etc.), as is done when using the camera lucida.

\section{RESULTS}

The results are based on retrograde transport from the $\mathrm{CN}$ in 24 animals. Figure 2 shows two representative injections into the $\mathrm{CN}$. The injection sites ranged in size from small (Fig. 2A-D) to very large, encompassing much of the ventral $\mathrm{CN}$, most of the granule cell area, and part of the dorsal CN (Fig. 2E, F). These injections labeled cells in many brainstem nuclei, including the inferior colliculus and superior olivary complex, as well as in the temporal cortex. In some cases, the injection site spread into the adjacent middle or inferior cerebellar peduncles. Control injections of FluoroRuby or fluorescein dextran into the cerebellum and the cerebellar peduncles labeled cells in a variety of places known to project to the cerebellum (e.g., external cuneate nucleus, inferior olive, lateral reticular nucleus, pontine nuclei), but did not label cells in the temporal cortex. In cases with the largest injections, the tracer spread into the lateral extreme of the vestibular nuclei, making it possible that cortical cells that project to these nuclei were labeled (Nishiike et al. 2000). However, cortical projections to the vestibular nuclei arise from vestibular cortex, which is located outside the area of auditory cortex in guinea pigs (Ödkvist et al. 1973). The labeling in auditory areas in these cases was indistinguishable from cases in which the injections were confined to the $\mathrm{CN}$. We conclude that the encroachment of some injections into the lateral part of the vestibular nuclei did not label a significant number of cortical cells and does not affect our conclusions.

Following injections in the $\mathrm{CN}$, labeled cells were observed bilaterally in the temporal cortex (Fig. 3). We chose one representative case for illustration. Figure $4 \mathrm{~A}$ shows a reconstruction of an injection of red beads into the left $\mathrm{CN}$. The labeled cells in the temporal cortex were distributed similarly on the ipsilateral and contralateral sides (Fig. 4B,C). To relate the distributions to auditory areas, we reconstructed a surface view of cortex with the labeled cells indicated (Fig. 4D-F). The majority of labeled cortical cells were located in a broad distribution that included both A1 and DC (Fig. 4D,E). Additional cells may have been located in surrounding areas. Dorsally, labeled cells were located beneath the pseudosylvian sulcus (e.g., Fig. 4B, sections L1, L2; Fig. 4C, section R2), which is associated with the dorsorostral belt (DRB) and the "small field" (S) 

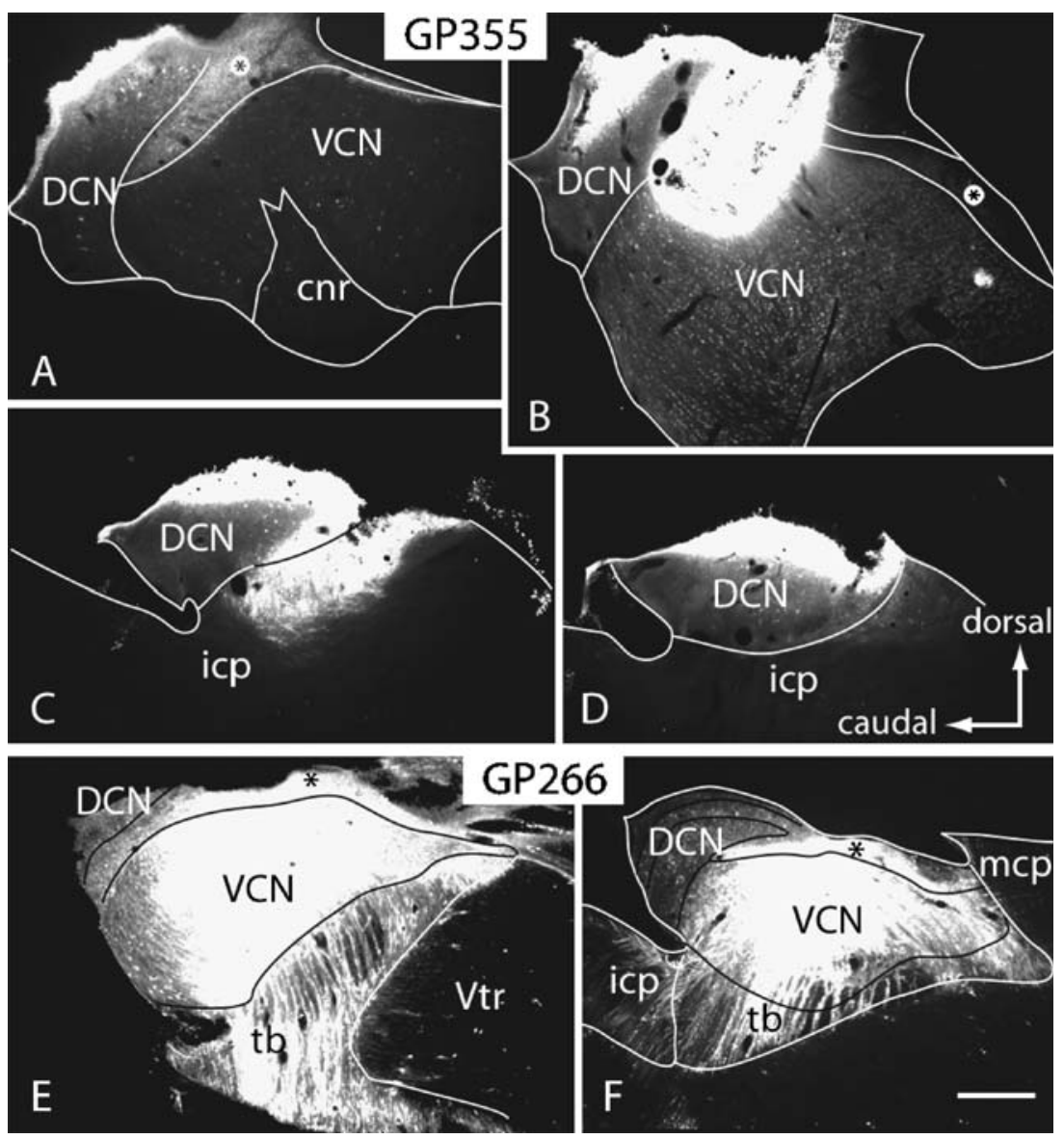

FIG. 2. Digital photomicrographs illustrating injections of fluorescent tracers into the $\mathrm{CN}$ in two different cases. (A-D) Fast Blue injection in case GP355. Sections are arranged from lateral (A) to medial (D). (E, F) FluoroRuby injections in case GP266. For all panels: parasagittal sections; dorsal is up; caudal is to the left. Scale

(Wallace et al. 2000, 2002b). Ventrally, labeled cells extended almost to the rhinal sulcus (e.g., Fig. 4B, sections L2, L4), suggesting that some cells are located within ventral belt areas (e.g., ventrocaudal belt, ventrorostral belt) as well as a more ventral cortical area. The identity of the latter area is unclear; apparently cells in this region are not easily driven by the types of acoustic stimuli used in earlier mapping studies (e.g., Wallace et al. 2000, 2002b). This same area contains a large number of labeled cells after injection of a retrograde tracer into the inferior colliculus (unpublished observations), so it seems likely that this region plays a role in auditory processing.

The number of labeled cells varied between cases. Some variation clearly occurred due to size and location of the injection, with the most cells being labeled by the largest injections and by those centered on the granule cell areas, which receive the largest number of cortical projections (Jacomme et al. 2003). In addition, there appeared to be bar $=0.5 \mathrm{~mm}$. cnr, cochlear nerve root; DCN, dorsal cochlear nucleus; icp, inferior cerebellar peduncle; $\mathrm{mcp}$, middle cerebellar peduncle; tb, trapezoid body; VCN, ventral cochlear nucleus; Vtr, spinal trigeminal tract; ${ }^{*}$, granule cell area.

differences due to the specific tracers used. Table 1 summarizes cell counts from six cases that, on visual inspection, contained the most labeled cells. The largest numbers of labeled cells were found after red bead injections. FluoroGold was the second most sensitive tracer in these cases, followed by green beads and Fast Blue. The fluorescent dextrans (FluoroRuby and fluorescein dextran) were particularly useful for assessing cell morphology because of extensive dendritic labeling (described below), but they generally labeled far fewer cells than the other tracers (data not shown); accordingly, we did not use them in cases for cell counts. The results indicate that over 16,000 cells could be labeled in the AC ipsilateral to the injection, and over 6000 cells contralateral to an injection. The total for the two sides reached 23,488 cells in one case. We assume that this number is an underestimate because it is unlikely that any injection labeled every cell in the pathway.

Inspection of Table 1 also shows that the relative number of labeled cells on the two sides varied from 


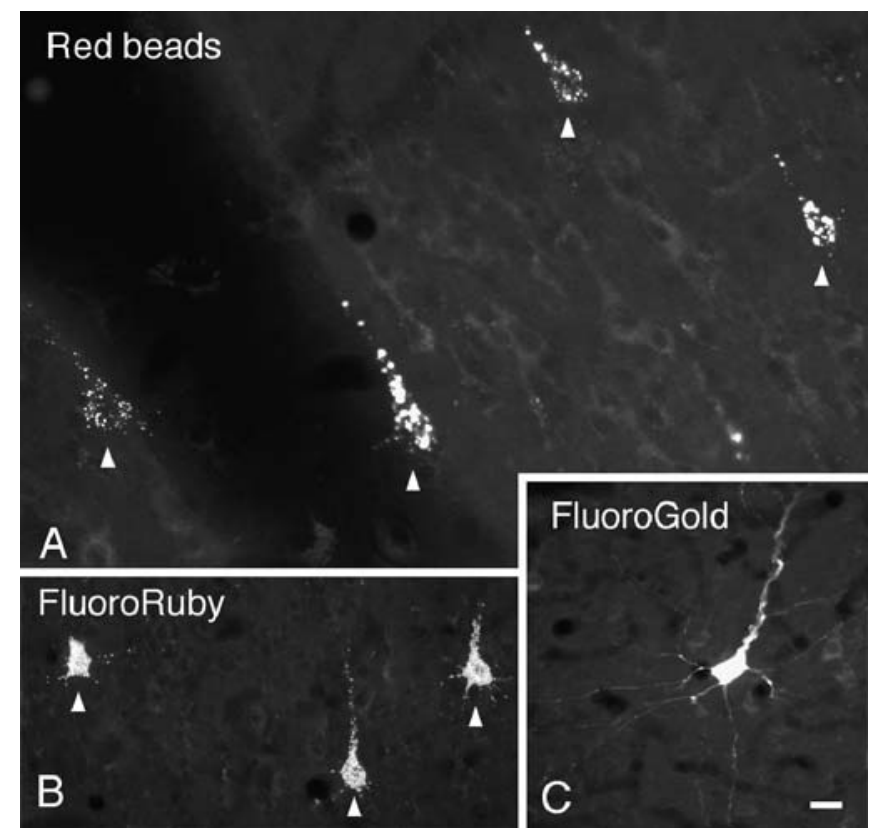

FIG. 3. Digital photomicrographs showing cortical cells labeled with various fluorescent tracers injected into the cochlear nucleus. (A) Cells in left cortex labeled by injection of red beads into the left cochlear nucleus. Case GP341. (B) Cells in left cortex labeled by

case to case. We quantified this variation by a simple ratio (ipsilateral/contralateral). Most often, the ipsilateral side contained more cells (ratio $>1$ ), but the sides were similar in two cases (402R, 403L) and the contralateral side predominated in two cases (398L, 399R). This variation characterized the entire set of cases (not just those quantified), with the majority of cases containing visibly more cells on the ipsilateral side. The variation in ratios was not easily attributed to differences between tracers, although subtle effects could not be ruled out. It seems likely that the differences between cases are attributable to some segregation in the termination of ipsilateral and contralateral projections in the $\mathrm{CN}$. injection of FluoroRuby into the right cochlear nucleus. Case GP304. (C) Cell in right cortex labeled by injection of FluoroGold into the right cochlear nucleus. Case GP247. Scale bar $=20 \mu \mathrm{m}$.

In all cases, the labeled cortical cells were located in layer $\mathrm{V}$. The cell bodies ranged from small to large, suggesting that the population might include multiple morphologic types (Fig. 5). Comparison of the two sides suggested that small to medium cells were present on both sides, but the largest cells were restricted to the ipsilateral side. This observation was confirmed by measuring the profile area of the labeled cell bodies in two cases (Fig. 6). The mean area of the ipsilateral cells was significantly larger than that of the contralateral cells $(p<0.05)$. The difference between cases in absolute areas probably results from differences in tissue shrinkage and/or differences in the tracers (FluoroRuby vs. red beads);
FIG. 4. (A) Line drawings of parasagittal sections through an injection site of red beads (solid black area) into the left cochlear nucleus. Sections progress from lateral to medial (left to right). cnr, cochlear nerve root; $\mathrm{DCN}$, dorsal cochlear nucleus; eCu, external cuneate nucleus; g, granule cell area; icp, inferior cerebellar peduncle; mcp, middle cerebellar peduncle; scp, superior cerebellar peduncle; tb, trapezoid body; VCN, ventral cochlear nucleus; Vest $n$, vestibular nerve; $\mathrm{VN}$, vestibular nuclei; $\mathrm{Vtr}$, spinal trigeminal tract. (B, C) Transverse sections through left (B) and right $(\mathbf{C})$ temporal cortex showing the locations of labeled cells resulting from the injection site in (A). Each triangle represents at least one labeled cell. Sections are numbered from rostral to caudal and are spaced $1200 \mu \mathrm{m}$ apart. Circles indicate the pseudosylvian sulcus (upper circle) and rhinal sulcus (lower circle). V, VI, cortical layers $\mathrm{V}$ and $\mathrm{VI}$, respectively; wm, white matter. (D, E) Surface reconstructions from the sections shown in (B) and (C) showing the distribution of labeled cells in left (D) or right (E) temporal cortex and their approximate relationships to auditory cortical areas as defined by Wallace et al. (2002b). The vertical lines indicate the locations of the transverse sections; section labels correspond to those in (B) and (C). Circles indicate the sulci and labeled cells are indicated by crosshatch. To simplify comparison, both reconstructions are presented with rostral to the right. (F) Schematic diagram of auditory cortical areas (modified from Wallace et al. 2002b, Fig. 6). A1, primary auditory cortex; DC, dorsocaudal auditory field; DRB, dorsorostral belt; $S$, small field; Som, somatosensory cortex; $\mathrm{T}$, transition area; VCB, ventrocaudal belt; VRB, ventrorostral belt; Vis, visual cortex. Case GP402. All scale bars $=1$ $\mathrm{mm}$. Orientation in each panel is indicated by arrows; D, dorsal; R, rostral; L, lateral. 
A

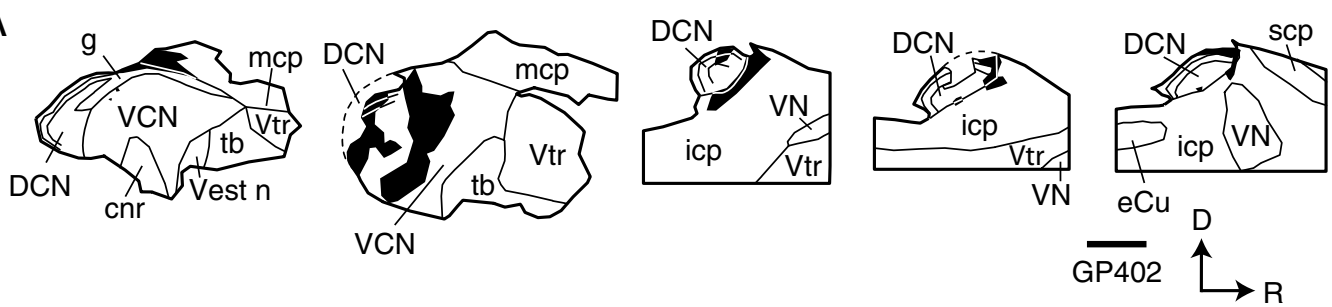

B IPSILATERAL

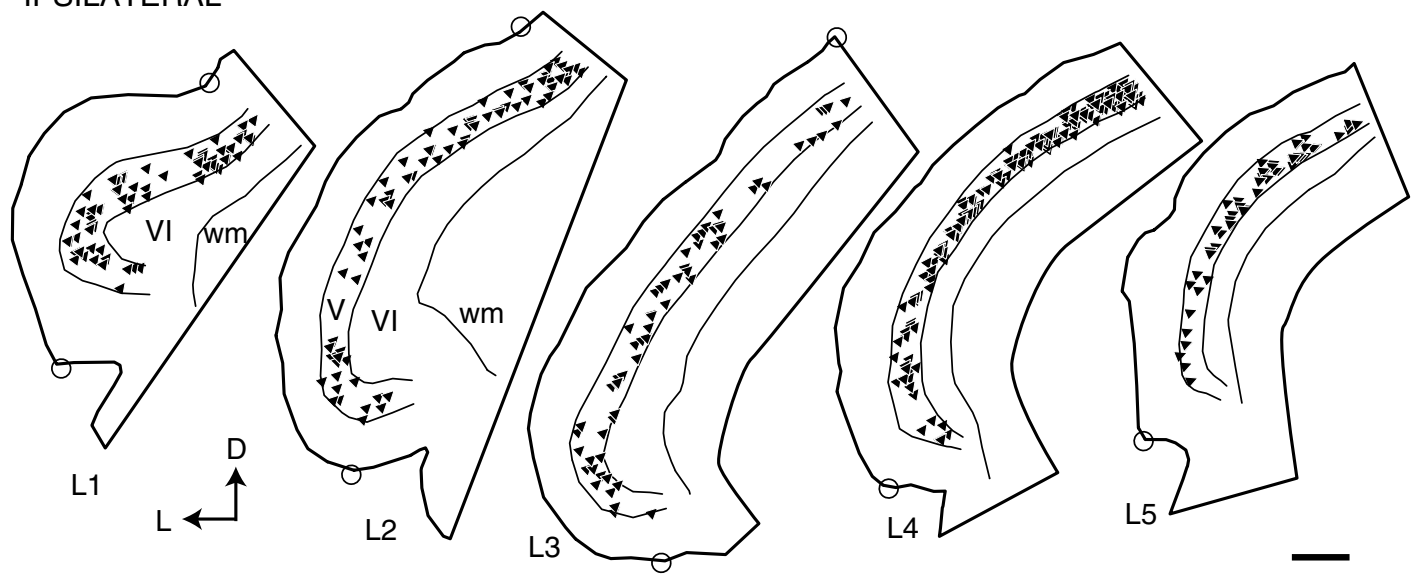

C CONTRALATERAL

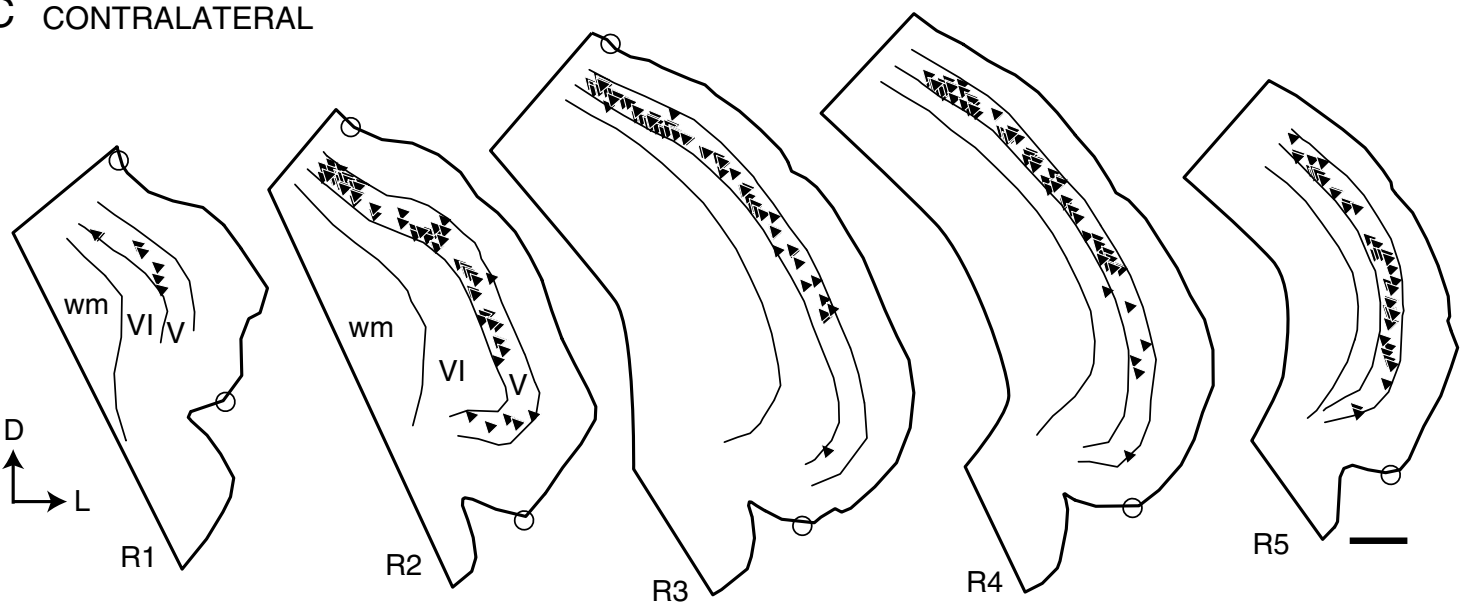

D

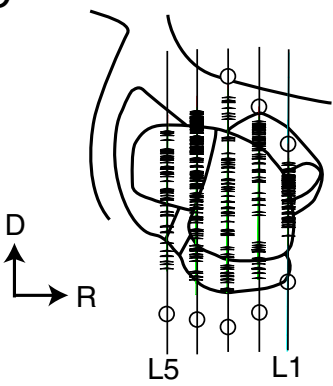

E

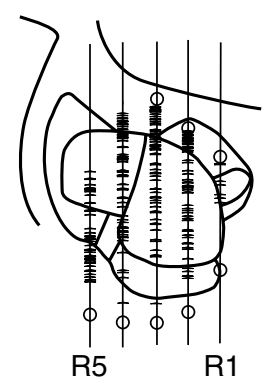

F

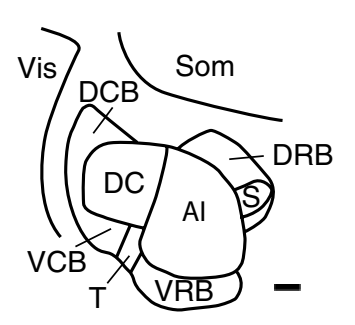

red bead labeled cell O pseudosylvian or rhinal sulcus 
TABLE 1

\begin{tabular}{|c|c|c|c|c|c|}
\hline \multicolumn{6}{|c|}{ Summary of cell counts } \\
\hline Case \# & Tracer & \# Ipsi cells & \# Contra cells & I/C ratio & \# Total cells \\
\hline $402 \mathrm{~L}$ & $\mathrm{RB}$ & 16,992 & 6,456 & 2.63 & 23,448 \\
\hline $400 R$ & RB & 13,872 & 4,176 & 3.32 & 18,048 \\
\hline $401 \mathrm{~L}$ & $\mathrm{RB}$ & 12,360 & 2,832 & 4.36 & 15,192 \\
\hline $402 R$ & FG & 5,928 & 6,096 & 0.97 & 12,024 \\
\hline $399 \mathrm{~L}$ & FG & 7,704 & 3,912 & 1.97 & 11,616 \\
\hline $398 \mathrm{~L}$ & FG & 1,752 & 4,116 & 0.43 & 5,868 \\
\hline 403L & RB & 2,352 & 3,000 & 0.78 & 5,352 \\
\hline 399R & GB & 1,104 & 2,208 & 0.50 & 3,312 \\
\hline $398 R^{a}$ & GB & 804 & 540 & 1.49 & 1,344 \\
\hline $400 L^{\mathrm{a}}$ & $\mathrm{FB}$ & 456 & 288 & 1.58 & 744 \\
\hline $401 R^{a}$ & $\mathrm{FB}$ & 288 & 168 & 1.71 & 456 \\
\hline Mean & & 7,758 & 4,100 & 1.87 & 11,858 \\
\hline SEM & & 2,141 & 534 & 0.50 & 2,446 \\
\hline Minimum & & 1,104 & 2,208 & 0.43 & 3,312 \\
\hline Maximum & & 16,992 & 6,456 & 4.36 & 23,448 \\
\hline Count & & 8 & 8 & 8 & 8 \\
\hline
\end{tabular}

\# Ipsi cells, number of cells in ipsilateral cortex; \# Contra cells, number of cells in contralateral cortex; I/C ratio, \# Ipsi cells/\# Contra cells. RB, red beads; FG, FluoroGold; GB, green beads; FB, Fast Blue; SEM, standard error of the mean.

${ }^{a}$ These cases were excluded from the statistical summary because of the low number of labeled cells (see text for discussion).

comparing ipsilateral and contralateral samples within cases controlled such sources of variation. In each case, the largest contralateral cells had an area $55-60 \%$ that of the largest ipsilateral cells.

Almost all the labeled cells had a clearly visible apical dendrite, and in many cases both apical and basal dendrites were well labeled (Fig. 7). It was of particular interest to determine whether the labeled pyramidal cells possess terminal dendritic tufts in layer I, because the presence of a tuft distinguishes two major classes of layer $\mathrm{V}$ pyramidal cells in many cortical areas (McCormick et al. 1985; Agmon and Connors 1989; Chagnac-Amitai et al. 1990; Kasper et al. 1994; Hefti and Smith 2000). Whereas only a minority of cells was labeled sufficiently to distinguish pyramidal types, dendritic tufts in layer I were labeled in numerous cases (Fig. 8). In one case in which dendrites were labeled extensively, we used serial reconstruction to obtain a more complete picture of the dendritic morphology (Figs. 9 and 10). The reconstructions confirmed the tufted morphology of the extensively labeled cells. Finally, tufts were labeled with three different tracers (FluoroRuby, FluoroGold, and Fast Blue). We did not observe any examples of well-labeled cells that did not exhibit a terminal dendritic tuft.

\section{DISCUSSION}

The present results characterize the cells of origin of a direct, bilateral projection from temporal cortex to the $\mathrm{CN}$ in guinea pigs. The results, obtained with retrograde tracers, corroborate those found with anterograde tracers (Jacomme et al. 2003; Schofield and Coomes, 2005a) and extend them with additional information on the morphology and distribution of the cells of origin of the projections. The projections arise from multiple auditory cortical areas. The cells of origin are restricted to cortical layer $\mathrm{V}$ and include cells with a dendritic tuft in cortical layer I. The following sections discuss the laterality of the projections as well as the cortical areas and types of layer V cells that contribute to the pathway. We compare our findings to those from rats, which is the only other species in which this pathway has been described in detail (Feliciano et al. 1995; Weedman and Ryugo 1996a, b). We then discuss the size of this projection relative to other descending auditory pathways and consider the functional implications.

\section{Ipsilateral versus contralateral projections}

The ipsilateral and contralateral projections differ in several ways. The largest labeled cells were found only ipsilateral to an injection. This finding differs from that in rats, where the two sides had a similar distribution of soma sizes (Weedman and Ryugo 1996a). Perhaps the largest cells represent a projection that is present in guinea pigs and not in rats; for example, the largest cells could be restricted to the dorsocaudal field. Visual inspection of our data suggested that this was not the case (at least some of the largest cells were located within A1). Alternatively, large cells could contribute to both ipsilateral 

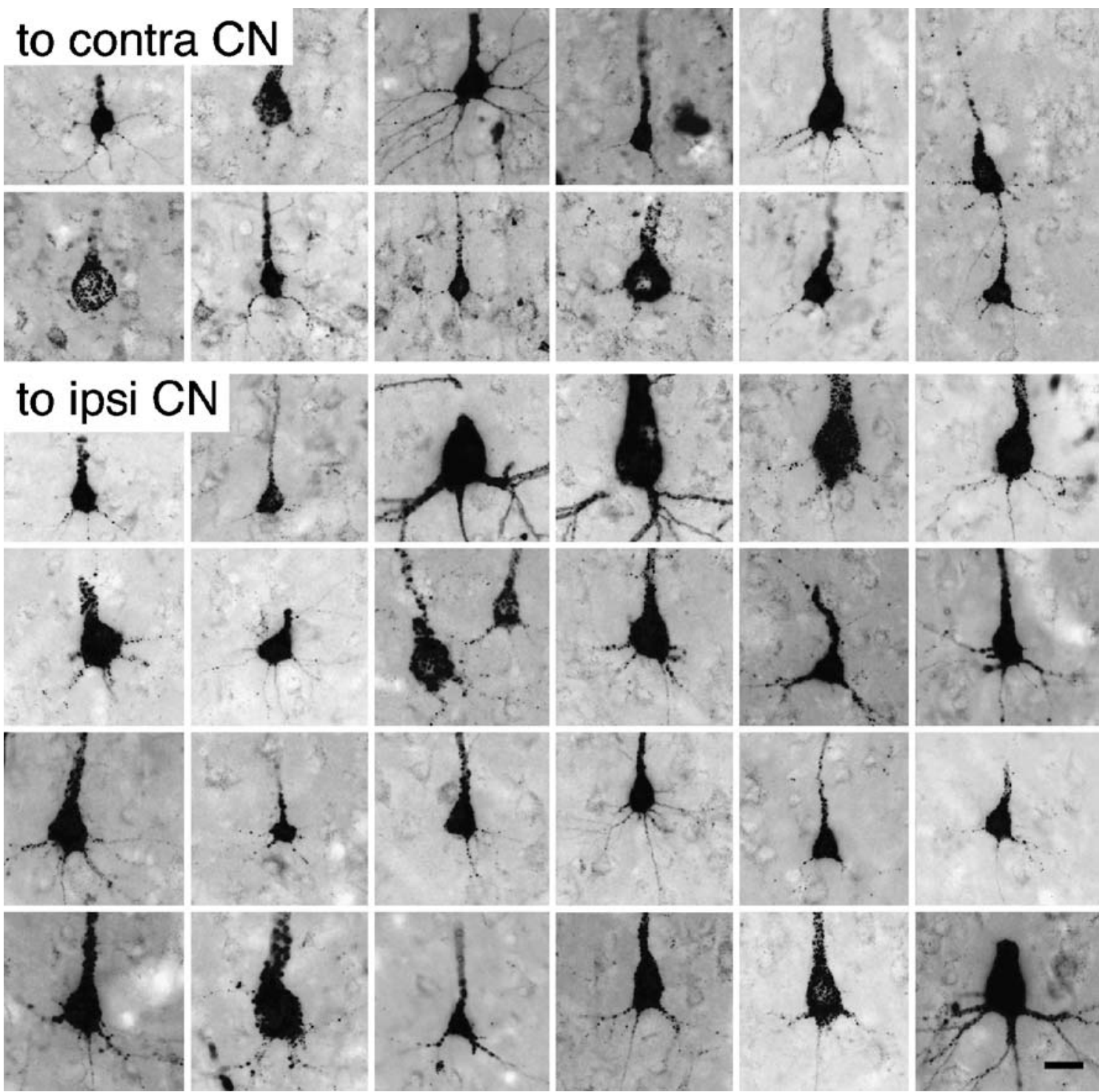

FIG. 5. Digital photomicrographs illustrating the variation in size of labeled cortical cells located contralateral (top two rows) or ipsilateral (bottom four rows) to an injection of FluoroRuby into the cochlear nucleus. All photographs are oriented so that the cortical surface is toward the top of the picture. Scale bar $=20 \mu \mathrm{m}$. Case GP304. Transverse sections. Note that contrast is inverted to improve visibility.

and contralateral projections in rats; clearly, further studies are needed to resolve this issue.

A second difference between ipsilateral and contralateral projections is in the ratio of ipsilateral to contralateral cells of origin, which varied considerably across cases. Following injection in one $\mathrm{CN}$, either side of cortex could contain the majority of labeled cells. This variability could be explained if the two projections terminate in nonoverlapping regions within the CN. Anterograde tracing experiments suggest that the projections to the two sides terminate in the same general areas (especially the granule cell area; Feliciano et al. 1995; Schofield et al. 2001; Jacomme et al. 2003), but perhaps the ipsilateral and contralateral axons are segregated within this target zone.
Injections of a retrograde tracer might then favor the ipsilateral target zone, or zones, in some cases and the contralateral target zone(s) in others. Experiments in which different anterograde tracers are injected into left and right cortex might reveal such segregation.

Anterograde tracing studies in rats also reveal variations related to laterality, with more axons labeled ipsilaterally in some cases and contralaterally in other cases (Feliciano et al. 1995). However, retrograde tracing experiments in rats produced a consistent bias, with the ipsilateral cortex containing two to three times the number of cells found in the contralateral cortex (Weedman and Ryugo 1996a). The reasons for this difference between rats and guinea pigs are unclear. 


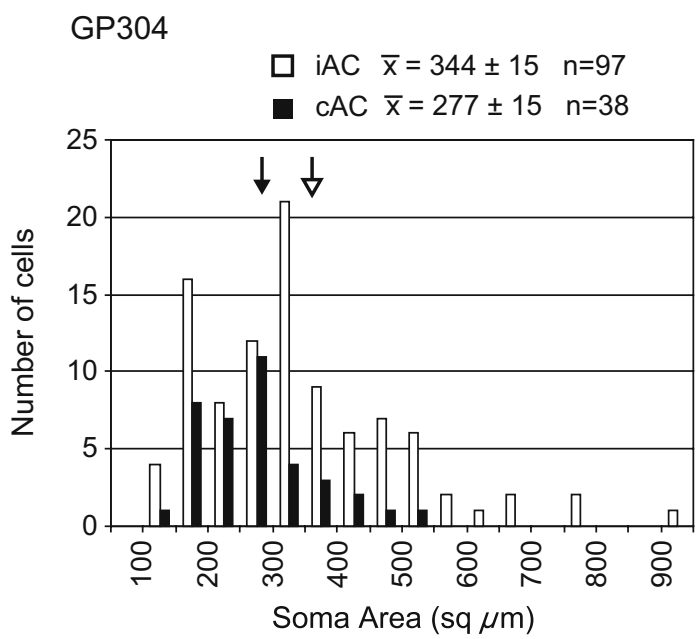

GP341

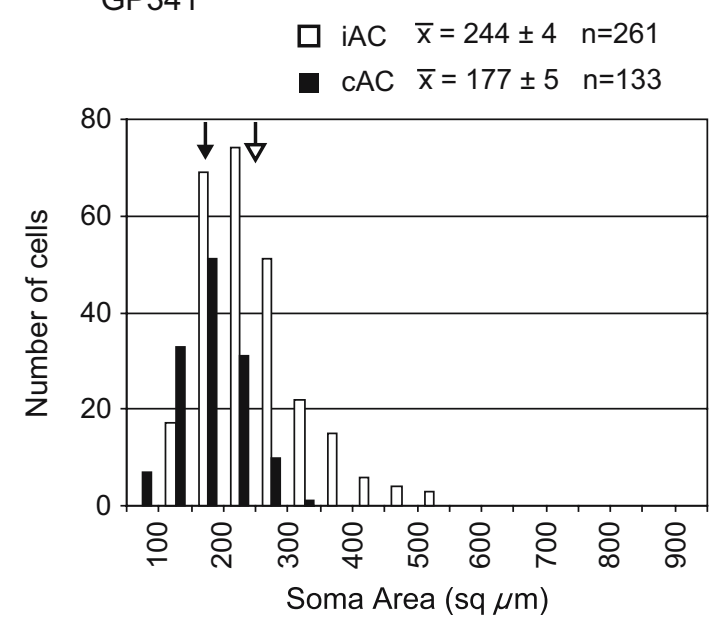

FIG. 6. Histograms showing the distribution of soma areas of cortical cells ipsilateral (iAC, white bars) or contralateral (cAC, black bars) to an injection in the cochlear nucleus. Results are shown for two cases. The mean area for each sample is shown with arrows (solid arrow for CAC; open arrow for iAC).

\section{Cortical areas}

The different auditory cortical areas have distinct physiological response properties and corticocortical connections, suggesting that they serve different functions (Rutkowski et al. 2002; Wallace et al. 2000, $2002 \mathrm{a}, \mathrm{b})$. The locations of the borders vary from animal to animal, making it impossible to localize the smaller areas (i.e., the belt areas) on strictly anatomical grounds (Wallace et al. 2000). Jacomme et al. (2003) used physiological mapping to guide injections of anterograde tracer into the primary auditory cortex or the dorsocaudal field in guinea pigs. Injections into either area labeled axons in the CN. Our results with retrograde tracers agree with the anterograde findings, and suggest further that some of the surrounding belt areas also project to the $\mathrm{CN}$; this point will have to be confirmed with electrophysiological identification of the cortical areas.
In rats, the cortical projections to the $\mathrm{CN}$ arise exclusively from area TE1, a region often considered equivalent to the primary auditory cortex (Weedman and Ryugo 1996a). Anatomical and physiological studies suggest that area TE1 may contain more than one auditory area (Herbert et al. 1991; Doron et al. 2002). For example, Doron et al. (2002) describe a rostral field in TE1 that is similar to A1 in other species, and a posterior field in TE1 that is physiologically distinct from A1. The differences imply that the corticofugal projections from these regions serve distinct functions. It would be interesting to determine whether the cortical projection to the $\mathrm{CN}$ in rats, like that in guinea pigs, contains contributions from multiple cortical areas.

\section{Cell morphology}

Layer V pyramidal cells exhibit a variety of morphologic classes (Winer 1992; Winer and Prieto 2001). Correlated physiological and morphological studies have separated pyramidal cells into two major types (McCormick et al. 1985; Mitani et al. 1985; Agmon and Connors 1989; Chagnac-Amitai et al. 1990; Larkman and Mason 1990; Ojima et al. 1992; Kasper et al. 1994; Hefti and Smith 2000, 2003). In the most common terminology, these types are named according to their characteristic responses to current injection: regular spiking (RS) and intrinsically bursting (IB). The two types have different dendritic morphologies and membrane properties, receive different patterns of thalamic inputs, different patterns of inhibitory inputs, and have different patterns of local axonal projections (McCormick et al. 1985; Mitani et al. 1985; Agmon and Connors 1989; Chagnac-Amitai et al. 1990; Ojima et al. 1992; Wang and McCormick 1993; Kasper et al. 1994; Hefti and Smith 2000). IB cells have an apical dendrite with a prominent tuft in layer I. Cells with tufted morphology are sources of many subcortical projections (e.g., Klein et al. 1986; Schofield et al. 1987; Hallman et al. 1988; Wang and McCormick 1993; Kasper et al. 1994; Winer and Prieto 2001). In contrast, RS cells lack a prominent layer I dendritic tuft. Nontufted cells are often associated with corticocortical and corticostriatal projections (e.g., Hallman et al. 1988; Hübener and Bolz 1988; Buhl and Singer 1989; Hübener et al. 1990; Ojima et al. 1992; Winer and Prieto 2001). The many differences imply that tufted and nontufted cells play distinct functional roles.

Layer $\mathrm{V}$ pyramidal cells in guinea pig auditory cortex can also be divided into tufted and nontufted groups (unpublished observations). It remains to be determined whether these cells correspond to IB and RS physiological classes, but this seems likely given the presence of such a correlation in a variety of 


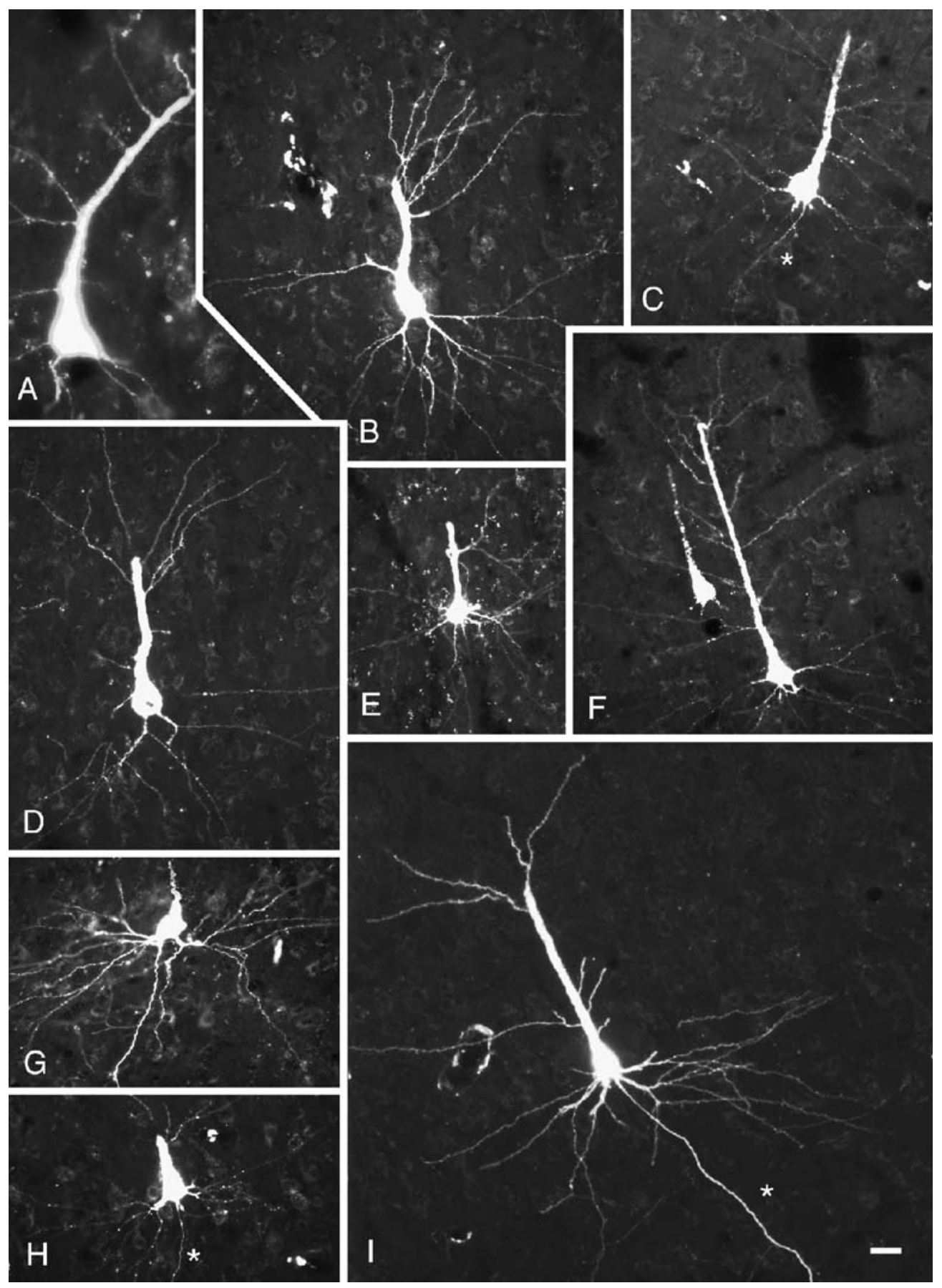

FIG. 7. Digital photomicrographs showing cortical cells, dendrites, and axons $\left(^{*}\right)$ labeled by injection of FluoroRuby into the cochlear nucleus. The photographs were taken from three different animals: GP266 (A, E, I); GP304 (B-D, F, H), and GP317 (G). The cells in (E) and (G) were located ipsilateral to the injection; the remaining cells were located contralateral to the injection. Scale bar $=25 \mu \mathrm{m}$. Transverse sections.

cortical areas and species: guinea pig (sensorimotor cortex: McCormick et al. 1985; Wang and McCormick 1993; visual cortex: Wang and McCormick 1993; cingulate cortex: McCormick et al. 1985), rat (auditory cortex: Hefti and Smith 2000; somatosensory cortex: Chagnac-Amitai et al. 1990; visual cortex: Kasper et al. 1994; Larkman and Mason 1990;
Chagnac-Amitai et al. 1990), and mouse (somatosensory cortex: Agmon and Connors 1989).

The present results indicate that tufted cells contribute to both ipsilateral and contralateral projections to the CN. Whether nontufted cells also project to the $\mathrm{CN}$ is unclear. Although we never observed well-labeled nontufted cells, we did observe 


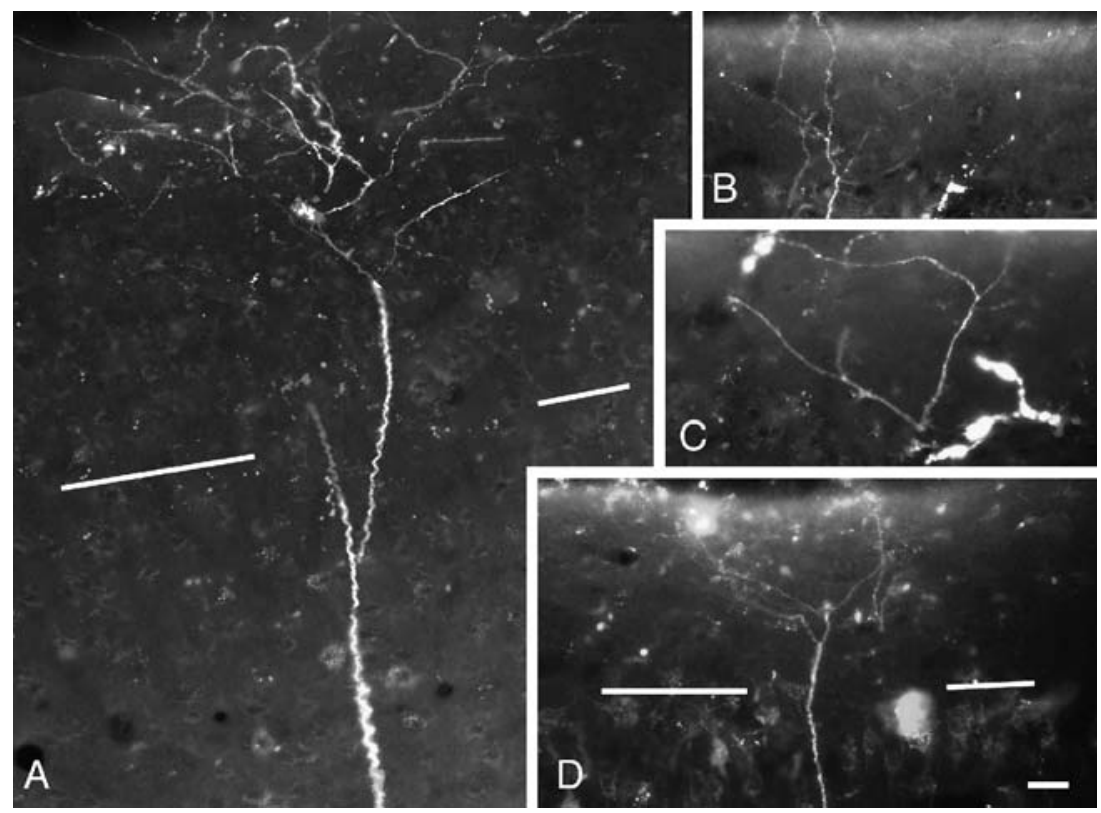

FIG. 8. Digital photomontages showing apical dendrite terminal tufts in layer I of auditory cortex. The cortical surface is at the top of each panel. The border between layers I and II is indicated by white lines in (A) and (D). (B and $\mathbf{C}$ are confined to layer I). (A) and (B) are from case GP317; (C) and (D) are from case GP304. Scale bar $=20 \mu \mathrm{m}$ for $(\mathbf{A}-\mathbf{C}), 40 \mu \mathrm{m}$ for $(\mathbf{D})$.

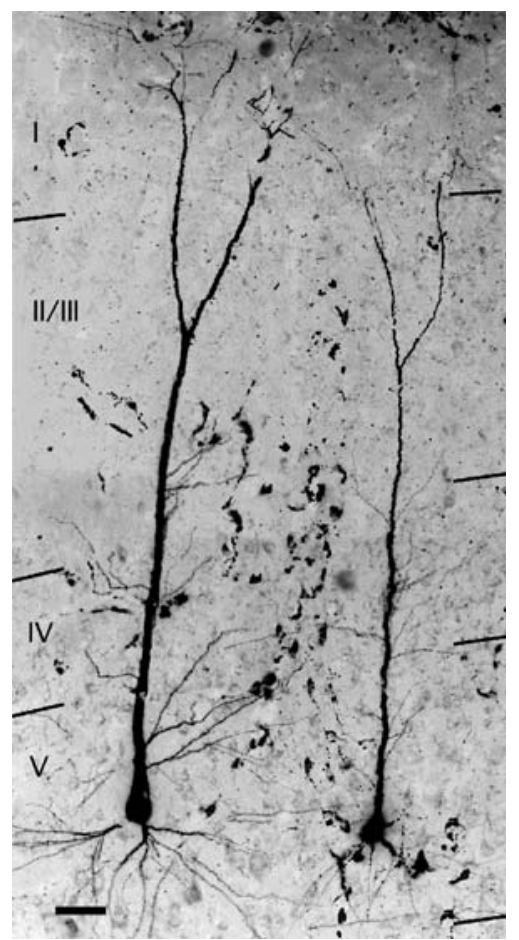

FIG. 9. Digital photomontage from 12 serial sections showing photographic reconstructions of two cortical cells that were labeled by an injection of FluoroRuby into the ipsilateral cochlear nucleus. Images were captured in color, converted to gray scale and contrastinverted to improve visibility of the label. Laminar borders are indicated by the black lines. Note that layer I appears unusually thick as a result of stacking 12 sections. Adobe Photoshop was used to adjust brightness and contrast along seams of montage components. Case GP304. Scale bar $=50 \mu \mathrm{m}$. many labeled cells with small cell bodies, which have been associated with nontufted morphology and RS physiology (e.g., Chagnac-Amitai et al. 1990; Ojima et al. 1992; Hefti and Smith 2000; Winer and Prieto 2001). Additional experiments, perhaps with retrograde "tagging" of AC-CN cells followed by intracellular labeling in a fixed slice (e.g., Hallman et al. 1988), could clarify the dendritic morphology of the cells with small somas and demonstrate whether nontufted cells project to the CN. This issue is particularly important given the many physiological distinctions between tufted ("intrinsically bursting") and nontufted ("regular spiking") cells and their likely differences in function.

\section{Functional implications}

One can reasonably ask about the significance of a pathway that has been demonstrated in only two species (rat and guinea pig) and that arises from relatively few cells compared to, say, the cortical projection to the thalamus or inferior colliculus. Our data suggest that there are as many as 23,000 AC-CN cells (approximately 17,000 ipsilateral and 6,000 contralateral). This number is considerably larger than the approximate 700-1200 cells in this pathway in rats (Weedman and Ryugo 1996a; Doucet et al. 2002; 2003). One possible explanation for the difference is that the projection originates from multiple cortical areas in guinea pigs but only from A1 in rats (Weedman and Ryugo 1996a). A second 


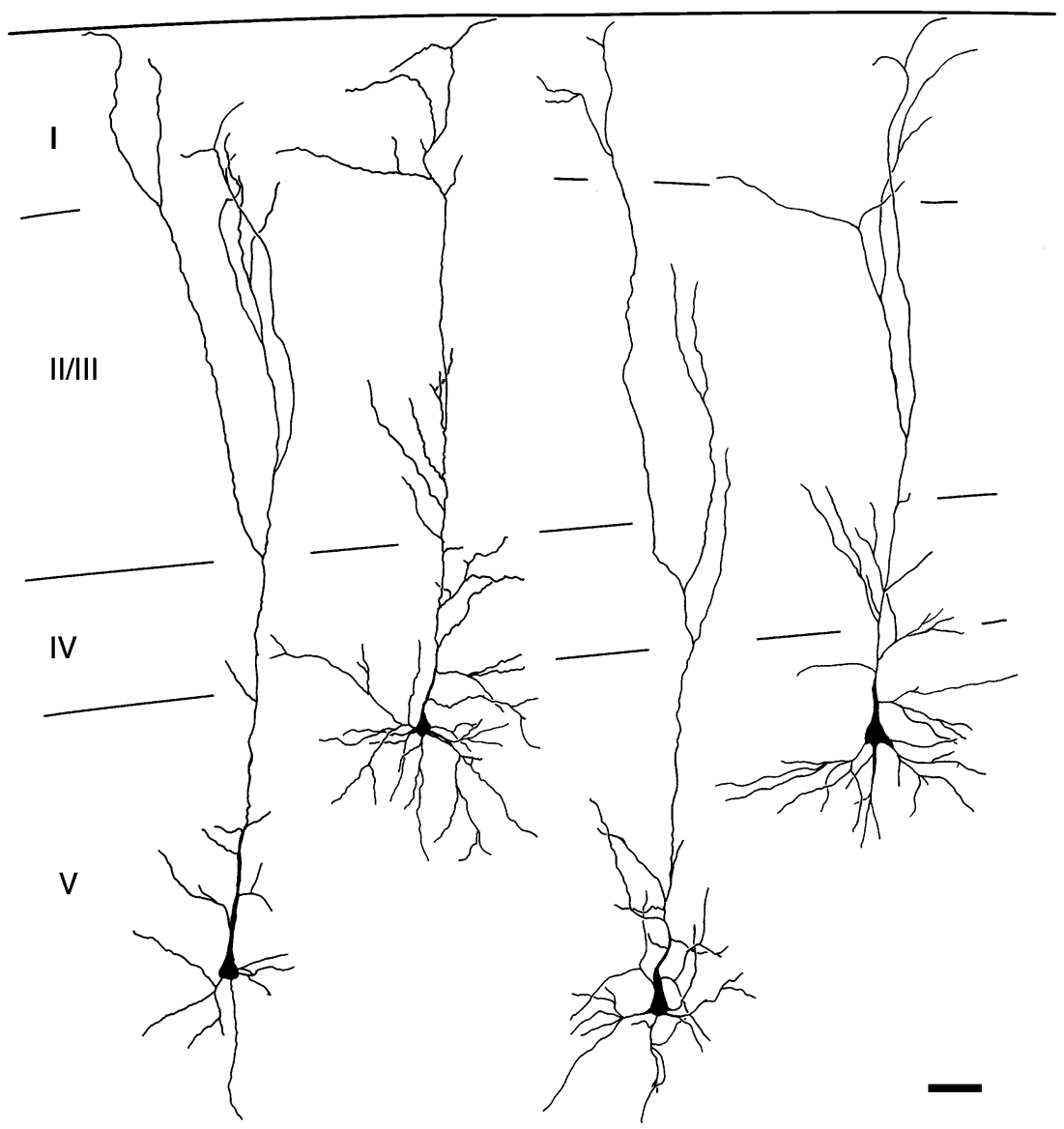

FIG. 10. Camera lucida drawings of four cortical cells reconstructed from serial sections. The cells were labeled by transport of FluoroRuby from the ipsilateral cochlear nucleus. The cells were located in different sections; the drawing does not indicate their positions relative to one another. Laminar borders are indicated by the black lines. Case GP304. Scale bar $=50 \mu \mathrm{m}$.

possibility relates to differences in tracer sensitivity. We found the largest number of cells with red bead injections, followed by FluoroGold. Green beads and Fast Blue labeled even fewer cells in our experiments (Table 1). Our largest estimate with Fast Blue was 744 cells (case GP400L, Table 1), a value within the range of that described in rats, which was also obtained with Fast Blue. It is possible that other tracers may reveal more AC-CN cell in rats.

How big is the AC-CN pathway compared to other descending auditory pathways? Olivocochlear cells have been counted in eight species and range from 475 in mouse to 2346 in guinea pigs (Warr 1992). Another descending pathway, from the AC to the superior olivary complex, has been estimated to originate from 1200 to 2000 cells in rats (Doucet et al. 2002, 2003). Another large descending pathway is the corticocollicular projection, which also originates from layer $\mathrm{V}$ cells in auditory cortex. The corticocollicular pathway comprises about 14,500 cells in rats, and thus is $5-10$ times the size of the projection from cortex to the CN (Weedman and Ryugo, 1996a; Doucet et al. 2003). In the course of other studies, we have injected different tracers into one $\mathrm{CN}$ and one inferior colliculus (Coomes and Schofield 2004b). In these cases, the corticocollicular cells outnumber the AC-CN cells, usually by several fold. We concur with Weedman and Ryugo (1996a) that the AC-CN pathway is smaller than the corticocollicular pathway, but is similar in size to some other descending pathways and thus likely to have a significant influence on $\mathrm{CN}$ circuitry.

The direct AC-CN projection is parallel to several other pathways by which cortical projections could influence CN cells. These include disynaptic pathways through the inferior colliculus (Coomes and Schofield 2002) and the superior olivary complex (Coomes and Schofield 2001). Cortical projections also appear to contact olivocochlear cells, which could alter the afferent signal that reaches the CN from the auditory nerve (Mulders and Robertson 2000). Each of these pathways could contribute to "higher order" effects on CN activity. Further work will be needed to identify the functional roles of the different pathways and the contributions of different cell types within each pathway. 


\section{ACKNOWLEDGMENTS}

Special thanks to Ms. Steva Stephens and Mr. Arkadiusz Slusarczyk for expert technical assistance. Dr. Martha Bickford provided valuable comments on an earlier draft of the paper. This study was supported by NIH DC04391 and DC05277.

\section{REFERENCES}

Agmon A, Connors BW. Repetitive burst-firing neurons in the deep layers of mouse somatosensory cortex. Neurosci. Lett. 99:137141, 1989.

BuHL EH, Singer W. The callosal projection in cat visual cortex as revealed by a combination of retrograde tracing and intracellular injection. Exp. Brain Res. 75:470-476, 1989.

Chagnac-Amitai Y, Luhmann HJ, Prince DA. Burst generating and regular spiking layer 5 pyramidal neurons of rat neocortex have different morphological features. J. Comp. Neurol. 296:598613,1990 .

Coomes DL, Schofield BR. Cortical projections to the superior olivary complex contact cells that project to the cochlear nucleus in guinea pigs. Assoc. Res. Otolaryngol. 24:45, 2001.

Coomes DL, Schofield BR. Do cortical projections contact both ascending and descending brainstem auditory pathways? Assoc. Res. Otolaryngol. 25:114, 2002.

Coomes DL, Schofield BR. Projections from the auditory cortex to the superior olivary complex in guinea pigs. Eur. J. Neurosci. 19:2188-2200, 2004a.

Coomes DL, Schofield BR. Projections from individual cortical cells to multiple targets in the auditory brainstem in guinea pigs. Assoc. Res. Otolaryngol. 27:120, 2004b.

Desmedt JE. Neurophysiological mechanisms controlling acoustic input. In: Rasmussen GL, Windle WF (eds) Neural Mechanisms of the Auditory and Vestibular Systems. C. C. Thomas, Springfield, IL, pp. 152-164, 1960.

DESMEDT JE. Auditory-evoked potentials from cochlea to cortex as influenced by activation of the efferent olivo-cochlear bundle. J. Acoust. Soc. Am. 34:1478-1496, 1962.

Dewson JH, Nobel KW, Pribram KH. Corticofugal influence at cochlear nucleus of the cat: some effects of ablation of insulartemporal cortex. Brain Res. 2:151-159, 1966.

Doron NN, Ledoux JE, Semple MN. Redefining the tonotopic core of rat auditory cortex: physiological evidence for a posterior field. J. Comp. Neurol. 453:345-360, 2002.

Doucet JR, Rose L, Ryugo DK. The cellular origin of corticofugal projections to the superior olivary complex in the rat. Brain Res. 28-41, 2002.

Doucet JR, Molavi DL, Ryugo DK. The source of corticocollicular and corticobulbar projections in area Tel of the rat. Exp. Brain Res. 153:461-466, 2003.

FAYE-LUND H. The neocortical projection to the inferior colliculus in the albino rat. Anat. Embryol. 173:53-70, 1985.

Faye-Lund H. Projection from the inferior colliculus to the superior olivary complex in the albino rat. Anat. Embryol. 175:35-52, 1986.

Feliciano M, Saldaña E, Mugnaini E. Direct projections from the rat primary auditory neocortex to nucleus sagulum, paralemniscal regions, superior olivary complex and cochlear nuclei. Auditory Neurosci. 1:287-308, 1995.

GAMES KD, Winer JA. Layer V in rat auditory cortex: projections to the inferior colliculus and contralateral cortex. Hear. Res. 34:126, 1988.
Giraud AL, Garnier S, Micheyl C, Lina G, Chery-Croze S. Auditory efferents involved in speech-in-noise intelligibility. NeuroReport 8:1779-1783, 1997.

Guillery RW. On counting and counting errors. J. Comp. Neurol. 447:1-7, 2002.

Hackney CM, Osen KK, Kolston J. Anatomy of the cochlear nuclear complex of guinea pig. Anat. Embryol. 182:123-149, 1990.

Hallman LE, Schofield BR, Lin CS. Dendritic morphology and axon collaterals of corticotectal, corticopontine, and callosal neurons in layer $\mathrm{V}$ of primary visual cortex of the hooded rat. J. Comp. Neurol. 272:149-160, 1988.

Harrison JM, Howe ME. Anatomy of the descending auditory system (mammalian). In: Keidel WD, Neff WD (eds) Handbook of Sensory Physiology. Vol. V, Part 1. Springer-Verlag, New York, pp. 364-388, 1974.

Heftr BJ, Sмiтh PH. Anatomy, physiology, and synaptic responses of rat layer $\mathrm{V}$ auditory cortical cells and effects of intracellular GABA(A) blockade. J. Neurophysiol. 83:2626-2638, 2000.

Hefti BJ, Sмith PH. Distribution and kinetic properties of GABAergic inputs to layer $\mathrm{V}$ pyramidal cells in rat auditory cortex. J. Assoc. Res. Otolaryngol. 4:106-121, 2003.

Herbert H, Aschoff A, Ostwald J. Topography of projections from the auditory cortex to the inferior colliculus in the rat. J. Comp. Neurol. 304:103-122, 1991.

HÜBENER M, Bolz J. Morphology of identified projection neurons in layer 5 of rat visual cortex. Neurosci. Lett. 94:76-81, 1988.

Hübener M, Schwarz C, Bolz J. Morphological types of projection neurons in layer 5 of cat visual cortex. J. Comp. Neurol. 301:655-674, 1990.

Huffman RF, Henson OW, JR. The descending auditory pathway and acousticomotor systems: connections with the inferior colliculus. Brain Res. Rev. 15:295-323, 1990.

Jacomme AV, Nodal FR, Bajo VM, Manunta Y, Edeline JM, Babalian A, RouilLer EM. The projection from auditory cortex to cochlear nucleus in guinea pigs: an in vivo anatomical and in vitro electrophysiological study. Exp. Brain. Res. 153:467-476, 2003.

Jen PHS, Chen QC, Sun XD. Corticofugal regulation of auditory sensitivity in the bat inferior colliculus. J. Comp. Physiol. A 183:683-697, 1998.

Kasper eM, Larkman AU, Lübke J, Blakemore C. Pyramidal neurons in layer 5 of the rat visual cortex. I. Correlation among cell morphology, intrinsic electrophysiological properties, and axon targets. J. Comp. Neurol. 339:459-474, 1994.

Klein BG, Mooney RD, Fish SE, Rhoades RW. The structural and functional characteristics of striate cortical neurons that innervate the superior colliculus and lateral posterior nucleus in hamster. Neuroscience 17:57-78, 1986.

LaRkMan A, Mason A. Correlations between morphology and electrophysiology of pyramidal neurons in slices of rat visual cortex. I. Establishment of cell classes. J. Neurosci. 10:1407$1414,1990$.

McCormick DA, Connors BW, Lighthall JW, Prince DA. Comparative electrophysiology of pyramidal and sparsely spiny stellate neurons of the neocortex. J. Neurophysiol. 54:782-806, 1985.

Mitani A, Shimokouchi M, Itoh K, Nomura S, Kudo M, Mizuno N. Morphology and laminar organization of electrophysiologically identified neurons in the primary auditory cortex in the cat. J. Comp. Neurol. 235:430-447, 1985.

MuLders WH, RoberTSON D. Evidence for direct cortical innervation of medial olivocochlear neurones in rats. Hear. Res. 144:65-72, 2000.

Nishitke S, Guldin WO, Baurle J. Corticofugal connections between the cerebral cortex and the vestibular nuclei in the rat. J. Comp. Neurol. 420:363-372, 2000.

Ödkvist LM, Rubin AM, Schwarz DWF, Frederickson JM. Vestibular and auditory cortical projection in the guinea pig (Cavia porcellus). Exp. Brain Res. 18:279-286, 1973. 
OJima H, Honda CN, Jones EG. Characteristics of intracellularly injected infragranular pyramidal neurons in cat primary auditory cortex. Cereb. Cortex 2:197-216, 1992.

Puel J-L, Bonfils P, Pujol R. Selective attention modifies the active micromechanical properties of the cochlea. Brain Res. 447:380 383,1988

RAJAN R. Electrical stimulation of the inferior colliculus at low rates protects the cochlea from auditory desensitization. Brain Res. 506:192-204, 1990.

Roger M, Arnault P. Anatomical study of the connections of the primary auditory area in the rat. J. Comp. Neurol. 287:339-356, 1989.

RouilLer EM. Functional organization of the auditory pathways. In: Ehret G, Romand R (eds) The Central Auditory System. Oxford University Press, New York, pp. 193-258, 1997.

Rutkowski RG, Shackleton TM, Schnupp JW, Wallace MN, Palmer AR. Spectrotemporal receptive field properties of single units in the primary, dorsocaudal and ventrorostral auditory cortex of the guinea pig. Audiol. Neurootol. 7:214-227, 2002.

Ryan A, Miller J. Effects of behavioral performance on single unit firing patterns in inferior colliculus of the rhesus monkey. J. Neurophysiol. 40:943-956, 1977.

Ryan AF, Miller JM, Pfingst BE, Martin GK. Effects of reaction time performance on single-unit activity in the central auditory pathway of the rhesus macaque. J. Neurosci. 4:298-308, 1984.

Ryugo DR, WeInBerger NM. Corticofugal modulation of the medial geniculate body. Exp. Neurol. 51:377-391, 1976.

RYUGo DR, WeInBERGER NM. Differential plasticity of morphologically distinct neuron populations in the medial geniculate body of the cat during classical conditioning. Behav. Biol. 22:275-301, 1978.

SALDAÑa E. Descending projections from the inferior colliculus to the cochlear nucleus in mammals. In: Merchán MA, Juiz J, Godfrey D, Mugnaini E (eds) The Mammalian Cochlear Nuclei: Organization and Function. Plenum Press, New York, pp. 153$165,1993$.

Scharf B, Quigley S, Aoki C, Peachey N, Reeves A. Focused auditory attention and frequency selectivity. Percept. Psychophys. 42:215-223, 1987.

Schofield BR, Coomes DL. Auditory cortical projections to the cochlear nucleus in guinea pigs. Hear Res 199, 89-102, 2005 a.

Schofield BR, Coomes DL. Projections from auditory cortex contact cells in the cochlear nucleus that project to the inferior colliculus. Hear Res 206, 3-11, 2005b.

Schofield BR, Coomes DL, Abel M, Schofield RM. Projections from the auditory cortex to the cochlear nucleus in guinea pigs. Assoc. Res. Otolaryngol. 24:44, 2001.

SChofield BR, Hallman LE, Lin CS. Morphology of corticotectal cells in the primary visual cortex of hooded rats. J. Comp. Neurol. 261:85-97, 1987.
Spangler KM, Warr WB. The descending auditory system. In: Altschuler RA, Bobbin RP, Clopton BM, Hoffman DW (eds) Neurobiology of Hearing: The Central Auditory System. Raven Press, New York, pp. 27-45, 1991.

Suga N, Gao E, Zhang Y, Ma X, Olsen JF. The corticofugal system for hearing: recent progress. Proc. Natl. Acad. Sci. USA 97:11807-11814, 2000.

Wallace MN, RUtKowski RG, Palmer AR. Identification and localization of auditory areas in guinea pig cortex. Exp. Brain Res. 132:445-456, 2000.

Wallace MN, Rutkowski RG, Palmer AR. Interconnections of auditory areas in the guinea pig neocortex. Exp. Brain Res. 143:106-119, 2002a.

Wallace MN, Shackleton TM, Palmer AR. Phase-locked responses to pure tones in the primary auditory cortex. Hear. Res. 172:160-171, 2002b.

WANG Z, McCormick DA. Control of firing mode of corticotectal and corticopontine layer $\mathrm{V}$ burst-generating neurons by norepinephrine, acetylcholine, and 1S,3R-ACPD. J. Neurosci. 13:2199-2216, 1993.

WARR WB. Organization of olivocochlear efferent systems in mammals. In: Webster DB, Popper AN, Fay RR (eds) The Mammalian Auditory Pathway: Neuroanatomy. Springer-Verlag, New York, pp. 410-448, 1992.

WeEdman DL, Ryugo DK. Pyramidal cells in primary auditory cortex project to cochlear nucleus in rat. Brain Res. 706:97-102, 1996 .

WeEdman DL, Ryugo DK. Projections from auditory cortex to the cochlear nucleus in rats: synapses on granule cell dendrites. J. Comp. Neurol. 371:311-324, 1996b.

WINER JA. The functional architecture of the medial geniculate body and the primary auditory cortex. In: Webster DB, Popper AN, Fay RR (eds) The Mammalian Auditory Pathway: Neuroanatomy. Springer-Verlag, New York, pp. 222-409, 1992.

Winer JA, Prieto JJ. Layer V in cat primary auditory cortex (AI): Cellular architecture and identification of projection neurons. J. Comp. Neurol. 434:379-412, 2001.

YAN J, Suga N. Corticofugal modulation of time-domain processing of biosonar information in bats. Science 273:1100-1103, 1996.

Zhang Y, Suga N. Corticofugal amplification of subcortical responses to single tone stimuli in the mustached bat. J. Neurophysiol. 78:3489-3492, 1997.

Zhang Y, Suga N, Yan J. Corticofugal modulation of frequency processing in bat auditory system. Nature 387:900-903, 1997.

Zimmerman EA, Chambers WW, Liu CN. An experimental study of the anatomical organization of the cortico-bulbar system in the albino rat. J. Comp. Neurol. 123:301-324, 1964. 